\title{
This and that: a procedural analysis
}

\section{Abstract}

In this paper I present a reanalysis of the English demonstrative determiners this and that. I assume a relevance-theoretic (Sperber and Wilson, 1986/95) approach to utterance interpretation in general and to reference resolution in particular, and argue that demonstratives encode procedural rather than conceptual meaning. In some cases this procedural meaning contributes to reference resolution directly and so affects the propositional content of an utterance. In other cases, however, the procedural information encoded by the determiner contributes to what is implicitly communicated by an utterance. This aspect of their use and interpretation has been largely overlooked by previous analyses, and taking it into consideration allows us to develop a unified account of the various and disparate roles they play.

Keywords: Demonstratives; Procedural meaning; Relevance theory

\section{Relevance and Reference}

\subsection{Introduction}

Identifying the intended referents of any referential expressions is part of the hearer's task in utterance interpretation. An adequate pragmatic theory should help to explain how reference resolution takes place. In this paper I take a relevance-theoretic approach to utterance interpretation, and consider the role that referring expressions generally, and demonstrative determiners specifically, play in the resolution process. According to relevance theory utterance interpretation comprises three subtasks: identification of the intended explicit 
content (explicatures), identification of the intended contextual assumptions (implicated premises) and identification of the intended contextual implications (implicated conclusions) (Wilson and Sperber, 2004:615). Reference resolution is generally considered to fall under the first of these subtasks. For example, in the utterance in (1), derivation of the explicit meaning involves identification of the intended referent for the pronouns he and her, so that the proposition expressed by the utterance would be something like (2).
(1) He saw her.
(2) SIMON $_{i}$ SAW CLARE $_{j}$

Since the truth conditions of the utterance depend on the proposition expressed, (1) will be true if and only if Simon saw Clare.

This paper argues that while the referring expression that the speaker chooses can play a crucial role in the first of the subtasks - derivation of explicit content -, it can also play a role in the remaining two subtasks - identification of the intended contextual assumptions and implications. That is, the speaker's choice of one particular referring expression over another may be driven by what she intends to imply, as well as by what she intends to explicitly communicate. This contribution to the speaker's overall intended meaning has largely been overlooked by existing accounts of demonstrative determiners, and I will argue that it is crucial if we are to understand the full range of uses of these expressions. 
In section 1.2, I introduce the main points of relevance theory and show how they apply to reference resolution. In section $1.3, \mathrm{I}$ introduce a distinction commonly drawn in relevance theory which will prove crucial to my analysis: the distinction between conceptual and procedural meaning.

In section 2, I turn to the question of how demonstratives function in referring expressions. In English, this and that and their plural counterparts these and those can occur on their own, as in (3), or as part of a complex noun phrase, as in (4), and they perform an apparently disparate range of functions which have been well documented in the literature (Chen, 1990; Cheshire, 1996; Cornish, 2001; Diessel, 1999; Fillmore, 1997; Glover, 2000; Huddleston and Pullum, 2002; Lakoff, 1974; Levinson, 2004; Kruisinga, 1925-32).

(3) This is fantastic.

(4) That cat looks angry.

Section 2.1 gives a brief overview of this literature, and section 2.2 critically surveys existing analyses which are broadly compatible with a relevance-theoretic approach. In section 3, I propose an alternative procedural analysis of demonstrative determiners which builds on notions central to the relevance-theoretic framework to offer a unified account of the meanings and functions of demonstratives.

\subsection{Relevance Theory and Resolving Reference}


Relevance theory (Blakemore, 1992; Carston, 2002; Sperber and Wilson, 1986/95; Wilson and Sperber, 2004, 2012) offers a cognitive approach to utterance interpretation based on two principles. The first, or cognitive, principle of relevance deals with cognition in general and states that human cognition tends to be geared towards the maximisation of relevance. The second, or communicative, principle of relevance deals specifically with communication, and states that "every act of ostensive communication communicates a presumption of its own optimal relevance" (Sperber and Wilson, 1986/95:260). Utterances, as acts of ostensive communication, fall under this principle. The heart of the relevance-theoretic approach to pragmatics thus lies in the definitions of relevance and optimal relevance. According to Sperber and Wilson, relevance is a "relation between an assumption and a context" (1986/95:123), and depends on two factors: cognitive effects and processing effort. At any one time, an individual will hold a set of existing assumptions about the world, from which a subset will be drawn to act as context for the processing of utterances or other inputs. Cognitive effects result when an input interacts with these contextual assumptions in one of three ways. The input may (a) strengthen an existing assumption, (b) contradict and eliminate an existing assumption or (c) combine with an existing assumption to yield contextual implications (conclusions derivable from the input and context together, but from 
neither alone). Other things being equal, the greater the cognitive effects achieved, the more relevant the input will be.

When cognitive effects are derived by processing an input in a context of existing assumptions, some mental effort is necessarily expended. This processing effort is the other factor in Sperber and Wilson's definition of relevance. Other things being equal, the less effort required to derive a given set of cognitive effects, the greater the relevance of the input ${ }^{1}$. Thus, cognitive effects and processing effort combine to make some potential inputs more relevant than others for a given individual at a certain time. According to relevance theory, the human cognitive system comprises a set of procedures which tend to maximise relevance by automatically allocating attention and processing resources to those inputs with the greatest expected relevance (Carston, 2002:44-47; Sperber, 2005; Sperber and Wilson, 1986/95:118-132; Wilson and Sperber, 2004).

However, according to Sperber and Wilson (1986/95), the addressee is not entitled to expect that the speaker, in producing an utterance or other ostensive stimulus, has aimed at maximal relevance, and that the utterance will therefore provide the maximum effects for the

\footnotetext{
${ }^{1}$ The level of effort required to process an utterance may be affected by a range of linguistic and nonlinguistic factors, including linguistic and logical complexity of the utterance, frequency or recency of use of linguistic constructions or conceptual representations, and the size and accessibility of the context.
} 
minimum effort, as compared with other possible utterances. Rather, the hearer is entitled to presume that any utterance addressed to him will achieve what is known as optimal relevance, and to interpret it accordingly. This presumption of optimal relevance is itself part of what is communicated by an utterance, and Sperber and Wilson define it as follows:

(5) Presumption of optimal relevance

(a) The ostensive stimulus is relevant enough for it to be worth the addressee's effort to process it.

(b) The ostensive stimulus is the most relevant one compatible with the communicator's abilities and preferences (1986/95:270).

This presumption in turn motivates the following comprehension procedure which, according to Sperber and Wilson, is automatically used in interpreting an utterance (or other ostensive stimulus):

(6) The Relevance-Theoretic Comprehension Procedure:

(a) Follow a path of least effort in computing cognitive effects. In particular, test interpretive hypotheses (disambiguations, reference resolutions, implicatures, etc.) in order of accessibility.

(b) Stop when your expectations of relevance are satisfied (2002:24). 
A consequence of this procedure is that the first accessible interpretation which makes the utterance relevant in the expected way is the one that the hearer should select. According to Sperber and Wilson (2002), the relevance-theoretic comprehension procedure is the central component of a comprehension module which automatically constructs an interpretation for any utterance (or other ostensive stimulus) addressed to one. Guided by considerations of relevance, a hearer, faced with the task of resolving reference, will follow the relevancetheoretic comprehension procedure. In any discourse context there may be more than one potential referent on which reference could be resolved. The hearer will test the most accessible one first. If that choice yields an overall interpretation that is relevant in the expected way, then he will accept that interpretation and look no further. To illustrate, consider the utterances in (7)-(9):

(7) The little boy looks like he is having fun.

(8) The little boy in the blue shirt looks like he is having fun.

(9) The little boy in the blue shirt and red cap looks like he is having fun.

In some cases, a representation of the intended referent, in this case a particular boy, may already be the most accessible one in the discourse context. If, for example, there is only one little boy in the room, then an utterance of (7) will be more felicitous (other things being equal) than an utterance of (8) or (9). However, if there is more than one little boy in the 
discourse context, then the speaker may add information to her referring expression to narrow down the set of potential referents to a point where a representation of the intended referent is once again the most accessible. One way of doing this is to add further information to the nominal part of the definite description, as in (8) and (9). As explained by Scott:

the discourse context can be viewed as including a set of potential referents, each of which can be mentally represented in a variety of more or less accessible ways, and the referring expression can be seen as a means by which the speaker may select a subset of the potential referents, such that a representation of the intended referent is the most accessible to the hearer in that subset (2011:189).

In examples (7)-(9), we can see how descriptive information in the nominal of the definite description performs this role. It is perhaps less clear what might be contributed by the demonstrative determiners in examples such as (3) and (4). To address this, it is necessary to introduce an important theoretical distinction which grew out of the relevance-theoretic framework: the distinction between conceptual meaning and procedural meaning. The next section introduces this crucial distinction.

\subsection{Procedural Meaning}


Relevance theory takes a largely computational-representational approach to cognition and communication (Fodor, 1983; Wilson and Sperber, 1993). On this approach, communication involves the construction and manipulation of a series of representations, phonetic, phonological, syntactic and conceptual, which are linked by a series of computations. Thus, the phonetic form of an utterance is seen as undergoing a linguistic decoding process to yield a semantic or logical form (or in the case of ambiguity, a set of logical forms). As decoding proceeds, the logical form is enriched via inferential pragmatic processes, including reference assignment, to yield a fully propositional form known as the proposition expressed or (if it is part of what the speaker is taken to communicate) the basic explicature. This basic explicature may itself be inferentially enriched to yield a series of higher-level explicatures carrying speech-act or attitudinal information (e.g. Mary believes that $P$; Mary is telling me that P). Moreover, explicatures may combine with contextual assumptions to provide input to further inferential processes yielding a series of contextual implications or implicatures (Carston, 2002, 2004; Sperber and Wilson, 1986/95). Thus, utterance interpretation involves a complex interaction between (linguistic and conceptual) representations and (linguistic and inferential) computations. Furthermore, the relevance of an utterance depends on the overall interpretation of that utterance in context, and the overall interpretation comprises both explicatures and implicatures. To derive the overall 
interpretation, the hearer must perform three distinct sub-tasks, which are typically carried out in parallel:

- Constructing an appropriate hypothesis about explicit content (explicatures) via decoding, disambiguation, reference resolution, and other pragmatic enrichment processes.

- Constructing an appropriate hypothesis about the intended contextual assumptions (implicated premises).

- Constructing an appropriate hypothesis about the intended contextual implications (implicated conclusions). (Wilson and Sperber, 2004:615)

The explicatures, implicated premises and implicated conclusions all contribute to the overall relevance of the utterance, and all three combine to make up (what the hearer takes to be) the speaker's meaning. Inferential pragmatic processes take place on both sides of the implicit / explicit divide.

A central feature of relevance theory is the claim that while most regular content words (e.g. boy, shirt) encode concepts that figure in conceptual representations, some expressions are better analysed in procedural terms, as contributing to the inferential, computational aspect of utterance interpretation. For instance, Blakemore argues that a range of non-truth-conditional discourse connectives (e.g. but, so, also) are best seen as 
encoding, not information which contributes directly to conceptual representations, but information about the type of inferential computations the hearer is expected to go through in constructing an overall interpretation (Blakemore, 1987). This work laid the foundations for an important theoretical distinction between conceptual and procedural encoding, which has played a major role in relevance-theoretic accounts of both verbal and non-verbal communication (Blakemore, 1987, 2002; Wharton, 2009; Wilson and Sperber, 1993). On this approach, conceptual encoding yields conceptual representations that figure directly in the explicatures that provide the input to further inferential computation, while procedural encoding places constraints on the types of representations to be constructed or the computations that are to take place (Blakemore, 1987, 2002, 2007; Hall, 2007; Wharton, 2003, 2009; Wilson, 2011). As Blakemore puts it, expressions that encode procedures 'do not encode a constituent of a conceptual representation (or even indicate a concept), but guide the comprehension process so that the hearer ends up with a conceptual representation' (2002:91).

Since this idea was first developed there have been various attempts to characterise the individual procedures encoded by different forms of expression (Blakemore, 2000, 2002; Hall, 2007; Hedley, 2007; Iten, 2005; Wharton, 2003; Wilson, 2011). As Wilson and Sperber point out, this is no easy matter, since we "have direct access neither to grammatical 
computations nor to the inferential computations used in comprehension" (1993:16). As a result, procedural meaning is not immediately available to introspection (Blakemore 2011;

Wilson 2011), and the best procedural analyses will be those that unify an apparently diverse array of surface effects. In recent years, the notion of procedural meaning has been quite widely used in analysing referring expressions in relevance theory, so that the pronoun she, for instance, is seen as encoding a procedure which narrows the search space for reference resolution to the set of female (or grammatically feminine) candidate referents (Hedley, 2007; Powell, 2010; Wilson and Sperber, 1993; Wilson and Wharton, 2006). Demonstratives, I suggest, like pronouns should be analysed as encoding procedural information.

Having established the theoretical framework in which my analysis will be based, I now introduce the data in more detail, and consider how existing accounts have analysed the various functions performed by demonstratives.

\section{An overview of demonstrative determiners}

\subsection{The uses of demonstratives}

Most surveys of the uses of demonstratives emphasise the wide range of functions they perform. Several take a taxonomic approach, dividing the demonstratives into various categories and sub-categories (Diessel, 1999; Fillmore, 1997; Lakoff, 1974; Levinson, 2004). 
Traditional grammars of English tend to draw the basic distinction between the

demonstrative determiners this and that in terms of spatial deixis (Huddleston and Pullum,

2002; Kruisinga, 1925-32; Quirk, et al., 1985). As Quirk et al. put it, "this and that contrast in

terms of the nearness of the referent to the speaker" (1985:374). In (10), the pen that is

requested is presented as distant from the speaker, whereas in (11), the speaker indicates

that she is referring to a proximal cake.

(10) Give me that pen

(11) This cake is delicious

However, attempts to understand how demonstrative determiners function have led to broad agreement that we must move beyond this traditional characterisation, (Anderson and Keenan, 1985; Halliday, 1985; Levinson, 2004; Lyons, 1977), and, indeed, much evidence suggests that this 'static' spatial analysis is inadequate (Cornish, 2001; Janssen, 1995; Maes, 1996; Strauss, 1993, 2002). Even broadly descriptive approaches allow that the notions of distance and proximity are at least partially subjective, and must be extended to include temporal, anaphoric and emotional uses. My aim in this section is to show that purely taxonomic approaches to the interpretation of demonstratives can only take us so far in understanding how they function. Indeed, once we examine the data in detail, the 
boundaries between supposed categories become blurred and arbitrary, further highlighting the inadequacy of these approaches.

Diessel (1999) makes a general division into exophoric and endophoric uses, and then goes on to identify multiple sub-types within each category (gestural, symbolic, anaphoric, discourse deictic, and recognitional). Levinson (2004) distinguishes between deictic and non-deictic uses, and similarly identifies various sub-categories (gestural (contrastive and non-contrastive), symbolic, transposed, discourse deictic, anaphoric, cataphoric, empathetic and recognitional). Levinson acknowledges that "the relations between these uses are probably more complex than this taxonomy suggests", and that there are many "borderline examples" and "fuzzy borders" (2004:107).

Spatial uses, such as (10) and (11), feature in all the taxonomies, and are perhaps the most intuitive of the categories. Fillmore calls them gestural uses and describes them as those uses which "can be properly interpreted only by somebody who is monitoring some physical aspect of the communication situation" (1997:62). Some physical demonstration of the intended referent, by gesture, eye-gaze, head nod or so on, must accompany the utterance for the use to be felicitous. As Fillmore puts it, "you will expect the word to be accompanied by a gesture or demonstration of some sort," (1997:63). The corresponding uses for Lakoff (1974:45) are "literal 'pointing' words", where this is used when the object is 
close to the speaker and that when it is further away, "particularly when contrasted with another closer" entity. Although Lakoff is not as explicit as Fillmore about the need for a demonstration to accompany the utterance, she does specify that this type of use "normally refers only to items literally in front of the speaker as he speaks" (Lakoff, 1974:46). Consider (12), uttered by a customer in a bakery. For the utterance to be felicitous, the objects referred to must be physically present and in some way indicated by the speaker:

(12) I'll take this loaf, that sausage roll and three of those buns.

Such cases would be considered 'gestural' by Fillmore and 'spatio-temporal' by Lakoff. Whilst 'spatial' uses seem straightforward enough under Lakoff's taxonomy, it remains unclear what she intends by the associated notion of a 'temporal' use. She gives no explicit examples of temporal uses in discussing the 'spatio-temporal' category, and it is unclear how such uses would differ from the anaphoric uses described below.

Diessel classifies the 'gestural' and 'spatial' uses as 'exophoric', and argues that they have three distinctive features which set them apart from other uses:

first, they involve the speaker (or some other person) as the deictic center, second they indicate a deictic contrast on a distance scale...and third, they are often accompanied by a pointing gesture (1999:94). 
Demonstratives may also be used to refer back or forward in a discourse, and examples such as (13) and (14) are, again, discussed in each of the taxonomies.

(13) John was late, and that made Mary angry.

(14) This is the plan: tell nobody.

Within this category, Diessel distinguishes between what he calls 'anaphoric demonstratives' which are "co-referential with a noun or noun phrase in the previous discourse" (ibid:95), and discourse demonstratives which refer to propositions, focusing "the hearer's attention on aspects of meaning expressed by a clause, a sentence, a paragraph or an entire story" (ibid:101). For example, the that in (15) refers to the embedded clause from John's utterance (that Mary will move to Hawaii).

(15) John: I've heard you will move to Hawaii?

Mary: Who told you that?

As with the spatial-deixis uses, there is broad agreement in the literature concerning the categorisation and function of the anaphoric uses of demonstratives. However, there remains a wide spectrum of cases which do not fall under these categories, and yet are legitimate and standard uses of demonstrative determiners. These are variously termed 'symbolic' (Fillmore, 1997), 'emotional' (Chen, 1990; Lakoff, 1974), 'recognitional' (Diessel, 
1999), 'empathetic' (Cornish, 2001) and 'affective' (Riddle, 2010), and they form an

apparently disparate group. The range of effects that they are claimed to produce is equally disparate. They are described variously as creating a sense of 'camaraderie' or 'closeness' in some cases, 'vividness' in other cases, such as (16), and as contributing to a sympathy effect in yet more cases, such as (17) (Chen, 1990; Lakoff, 1974)2:

(16) There was this travelling salesman, and he...

(17) How's that throat?

These 'emotional' uses are categorised slightly differently by different accounts. Diessel, who refers to them as 'recognitional' uses, takes a discourse-oriented approach. In his view, they signal that the information is 'discourse new', 'hearer old' and 'private'. 'Private' information is "information that speaker and hearer share due to common experience in the past", as opposed to "general cultural information" that is shared by all members of the speech community (1999:106). Thus, according to Diessel, this use of demonstratives suggests that the speaker and the hearer share the same viewpoint, and is therefore intended to indicate "emotional closeness, sympathy and shared beliefs" (ibid:107).

\footnotetext{
${ }^{2}$ As illustrated by examples (16) and (17) respectively, this can sometimes replace the indefinite article $a$, and that can substitute for the second-person pronoun your. Lakoff (1974) discusses the conditions on these substitutions in more detail.
} 
Cornish (2001), following Strauss (1993), Cheshire (1996) and Glover (2000), treats some 'emotional' (or 'empathetic', as he and Diessel term them) uses of that, such as (18), as creating a 'solidarity' effect:

(18) ..."Do we want machines which are more intelligent than humans, or should we call a halt to it?" he asked. "We are still a long way from that decision but I think..." (The Guardian cited in Cornish, 2001:303)

According to Cornish, the use of that indicates that the speaker does not want to be associated with the referent of the demonstrative phrase. Furthermore, "the speaker is tacitly instructing the addressee to place the referent outside his/her discourse-cognitive sphere", thus casting the hearer as "a potential ally in the speaker/writer's argumentative stance" (2001:304). This, Cornish claims, results in a solidarity effect.

Thus, while there is broad agreement that demonstratives have uses beyond their spatialdeixis and anaphoric functions, attempts to account for the nature of these other uses have been less unified. What the various classification schemes have in common is an association between these other 'emotional' uses and attitudinal effects of some sort. However, how or why a particular effect should arise on a particular occasion of use is generally less clear. Any account that aims to provide a comprehensive analysis of how demonstratives are understood must address this issue, and to do so should be able to 
answer two crucial questions. First, what is the underlying meaning of each determiner, and second, how are the other uses derived? Again, there are different approaches to these issues. Chen argues that the basic meanings of this and that are their spatial and temporal senses, and that all other uses are the result of semantic expansion. According to this approach, "[i]n their basic uses, this points to an object nearer to the speaker, that to an object far away from the speaker" (1990:144), and all of the other uses (camaraderie, sympathetic, contrastive, etc.) are the result of this basic meaning interacting with the "linguistic environment" (ibid:152). Diessel holds a similar position, claiming that the exophoric use is "basic and unmarked" (1999:114), with all other uses derived from it. Cornish argues that the derivation goes the other way, and that it is the 'modal' or 'empathetic' uses that are basic, and all the other uses that are derived (2001:312). In the sections that follow, I argue that we can account for the various functions of demonstrative determiners by taking a procedural approach to the meaning encoded by this and that. The full range of uses can be derived on the assumption that the underlying procedural meaning interacts with the discourse context, and the overall interpretation is constrained by considerations of relevance. I outline my procedural account in section 3 . However, a few previous analyses have taken a broadly procedural approach, and I will consider these briefly in the next section. 


\subsection{Procedural Approaches}

Despite the wide range of uses and effects identified by the various taxonomic accounts, several attempts have been made to formulate a unified analysis of demonstrative determiners within the scope of more general approaches to referring expressions. For the most part these rely on two influential accounts of how referring expressions function in discourse: Accessibility Theory (Ariel, 1990, 2001) and the Givenness hierarchy (Gundel, 2010; Gundel, et al., 1993; Gundel and Mulkern, 1998). Both accounts have been claimed to be compatible with the relevance-theoretic pragmatic framework, and both could be seen as broadly procedural in nature.

According to Accessibility Theory, when a speaker uses a referring expression, she is signalling to her hearer how accessible she believes the mental representation of the intended referent to be for that hearer in that particular context. Referring expressions are therefore viewed as markers which function by "cueing the addressee on how to retrieve the appropriate mental representation in terms of degree of mental accessibility" (Ariel 2001:31). Demonstrative determiners are characterised as marking what Ariel calls 'intermediate' accessibility. Within this intermediate range "more accessible entities are referred to by the proximal marker. Less accessible ones will be referred to by the distal ones" (Ariel,

1990:51). While the focus of Ariel's theory is explaining how reference is resolved, she also 
discusses the subtler effects that choice of a demonstrative determiner can have on

utterance interpretation. Consider the examples in (19) and (20):

(19) That holiday we spent in Cyprus was really something.

(20) The holiday we spent in Cyprus was really something.

According to Ariel, use of the demonstrative rather than the definite description in (19) has the effect of raising "into consciousness 'livelier pictures' of the said holiday" (ibid:54). The use of the intermediate Accessibility marker that signals that the speaker believes the referent is already familiar to both speaker and hearer. This is not necessarily the case with the lower accessibility marker the.

Like Ariel, Gundel et al. (1993) attempt to explain why speakers choose certain referring expressions in certain discourse contexts, and how hearers identify the intended referent from those expressions. Whereas Ariel claims that levels of Accessibility are encoded as part of the conventional meaning of referring expressions, Gundel et al. base their approach on the cognitive status (involving "information about location in memory and attention state") of the intended referent (1993:274). They propose that different forms of referring expressions "signal different cognitive statuses...thereby enabling the addressee to restrict the set of potential referents" (ibid:274-5). According to the Givenness hierarchy, use of a definite article signals that the intended referent is 'uniquely identifiable', use of a distal 
demonstrative signals that the referent is 'familiar', and use of a proximal determiner signals that the referent has the even higher cognitive status of being 'activated'3. Again, the choice of determiner is seen as guiding the hearer to the speaker's intended referent in a manner that could be seen as distinctly procedural in nature. Amfo (2007) applies the Givenness hierarchy approach to demonstratives in Akan.

Along similar lines, Strauss (2002) analyses the different forms of demonstrative as signalling different levels of 'focus', where focus is defined as "the force with which the hearer is instructed to seek the referent" (2002:135). Use of this signals that the speaker regards the information as important, and as therefore deserving of a high degree of focus. Use of that signals 'medium focus', and it signals low focus. On this account, a speaker's choice of referring expression is based on "spontaneous, contextually grounded interactional factors between the various participants involved in the talk" (ibid:133). These factors include the relationship between speaker and hearer, the amount of information they share, and the relative importance of the referent to the speaker.

Although these approaches differ in their details, all three seek to place their account of demonstratives within a cognitively-oriented analysis of referring expressions in general, and

\footnotetext{
${ }^{3}$ I refer here to the complex demonstrative forms this $N$ or that $N$. According to the Givenness hierarchy, bare demonstratives, both the distal that and proximal this, signal that the intended referent is 'activated'. See Gundel et al. (1993) for further discussion.
} 
they all move away from physical notions such as the referent's proximity to or distance from the speaker. They share the idea that the hearer is directed to a representation of the intended referent from amongst a set of candidate referents via information encoded by the various referring expression forms. Each of these broadly procedural approaches depends on the assumption that the different forms of referring expression form a hierarchy or scale. Whether they define the points on the scale as representing a degree of Accessibility, a cognitive status, or a level of focus, they share the idea that definite descriptions signal one status, proximal demonstratives another, and so on. On these accounts, it is the referring expression type that linguistically encodes the crucial information.

The account I propose in section 3 below is motivated in part by the desire to remove the extra theoretical layer of representation introduced by appeals to hierarchies or various scales. While they may be descriptively useful, I suggest that such scales of referring expression types are not psychologically plausible, and I agree with the opinion put forward by Leonetti that they:

should not be considered as primitives of a theory of anaphora resolution...but simply as statistical generalizations derived from the interaction of linguistic semantics and inferential processes. Far from being the explanatory principles 
for anaphoric relations, they need to be explained in terms of simpler and more fundamental notions (2000:8).

On my account, the pragmatic effects of a referring expression are not determined by the type of expression it is (definite description, pronoun, distal complex demonstrative, etc.), but by the particular concepts and procedures that it encodes. In each case the encoded content interacts with the particular discourse context to contribute to the overall interpretation of the utterance. Thus my account could be seen as an attempt to flesh out the details of the "linguistic semantics and inferential processes" that Leonetti sees as driving the patterns of use. Like Strauss and Cornish, I will move away from the idea that demonstratives encode purely physical notions of proximity and distance which relate to the "geographical location of their referents in relation to the speaker" (Cornish, 2001:306), and instead propose a more abstract proximity-based procedural account. I take inspiration from work by Reboul $(1998,1999)$ who situates her analysis more directly within the relevancetheoretic framework, and introduces the idea that demonstratives might encode non-truth conditional meaning that influences interpretation. Unlike Ariel, Gundel et al. and Strauss, however, she suggests that the difference between this and that has "to do with the relative distance between the speaker and the object designated" (Reboul, 1997:11), thus reintroducing the traditional appeal to proximity and distance. However, she remains rather 
vague about how this difference might be developed within a full account. In the next

section, I take Reboul's proposal that demonstratives encode non-truth conditional meaning as a starting point, although like Strauss and Cornish, I will move away from the idea that demonstratives encode purely physical notions of proximity and distance relating to the "geographical location of their referents in relation to the speaker" (Cornish, 2001:306), and go for a more abstract proximity-based account.

However, my main point is that demonstrative determiners encode procedural meaning which does not necessarily or only guide the hearer to the intended referent, but may in some cases contribute to what is implicitly communicated as well. This leads us towards a more unified account in which all uses and functions of demonstratives are derived from the same underlying, procedurally encoded meaning.

\section{Demonstratives and Procedures}

\subsection{A move away from procedural scales}

In section 2, I outlined the variety of uses to which demonstrative determiners may be put, and the wide range of effects they can produce. I showed how this has led to attempts to produce taxonomies of use, but argued that these were ultimately unsatisfactory. I then outlined some existing procedural accounts, and argued that they are problematic in that they propose procedures which are associated with the general referring expression types 
(pronoun, definite description, complex proximal demonstrative, etc.), rather than being derived from the linguistic semantics of the constituent parts of the expression.

On the account I propose, this and that each encode a procedure which is constant across uses so that they contribute the same procedure when used on their own, in examples such as (3)(This is fantastic), as they do when part of a complex demonstrative, as in (4) (That cat looks angry). This avoids the extra layer of representation implicit in the existing scalar accounts. In doing this I aim to answer two main questions. First, in section 3.2 , I focus on examples where choice of demonstrative affects the explicit content of the utterance. I ask what these data reveal about the encoded meaning of this and that, and go on to offer a procedural answer at the level of the determiners themselves. I then ask how a unitary procedural approach can account for the range of effects and uses associated with this and that. To answer this, I turn to the relevance-theoretic notions introduced in section 1.2 , and argue that the use, distribution and interpretation of demonstratives fall out naturally from an analysis where a hearer is expected to test interpretative hypothesis in order of accessibility and stop when the overall interpretation satisfies his expectations of relevance.

\subsection{Demonstrative procedures.}


I start my procedural account of demonstrative determiners by considering those cases where the choice of demonstrative clearly affects the explicit content of the utterance. Consider the examples in (21)-(24):

(21) I'll have a slice of this cake.

(22) I'll have a slice of that cake.

(23) We went for a lovely walk this afternoon.

(24) We went for a lovely walk that afternoon.

If (21) and (22) are uttered in the same discourse context where the speaker has been offered the choice of two cakes, we can imagine that reference might well be resolved differently in each case. Similarly, the resolution of the complex demonstratives in (23) and (24) will necessarily be different. In both pairs, the only difference is the form of the determiner, and in both cases, substitution of the complex demonstrative with a corresponding definite description will be infelicitous, as in (25) and (26).

(25) ? I'll have a slice of the cake.

(26) *We went for a lovely walk the afternoon. 
Although (25) is not ungrammatical in itself, it will be infelicitous in a discourse context where there are two cakes whose representations are equally accessible, since reference will not easily be resolved.

As the data in (21)-(26) show, choice of determiner can affect the proposition that an utterance is taken to express by affecting the reference resolution process. Use of a definite description rather than a complex demonstrative can lead to a different interpretation or to the utterance being judged infelicitous, and the choice between the distal and proximal demonstrative may also lead to reference being resolved on a different representation. Therefore, we need to consider what the procedural information encoded by the demonstratives might look like, and how the procedure encoded by the proximal form differs from that encoded by the distal form. To do this, I take as my starting point the traditional distal/proximal distinction often used to characterise the difference between this and that, and explore how we might generalise the notions of proximity and distance to apply to a much wider range of cases. In doing this, I depart from Ariel's and Gundel et al.'s procedural accounts, in which such traditional notions appear to play no role.

Powell (1998:18), who proposes a procedural approach based on the traditional distal/proximal distinction, suggests that this and that encode related, but different, two-step procedures. This encodes the procedure, "find the speaker and then find an object near the 
speaker"; for that, the procedure is the same except that the hearer expects to find an object far away from the speaker. This analysis is then extended to the plural forms, with these encoding the procedure, "find an object near the speaker and then find a plural referent relating to it", and mutatis mutandis for those. Powell's procedures are thus built around the notions of proximity to and distance from the speaker. I follow this approach in treating proximity and distance as relational terms. A candidate referent will be proximal or distal relative to some point of reference. Here, proximity and distance are not objective properties inherent in the referent itself, but depend on the context in which the utterance is processed, and will vary as elements of the discourse context vary. This is particularly evident in an exchange such as (27).

(27) Clare: Pass me that book.

Mary: This book?

Clare: Yes, that book.

In this case, each speaker assesses the proximity of the book relative to herself, and from her own point of view, so that the same entity is referred to using both the distal and proximal forms. Once the book has been passed to Clare, she may then utter (28) and still be understood as referring to the same item.

(28) I love this book. 
From a relevance-theoretic perspective, drawing attention to the relative proximity of an entity will be relevant if it reduces the effort involved in reference resolution, either by adding an extra layer of activation to the hearer's mental representation of the intended referent, or by ruling out any non-intended competitors. If the relative proximity of the intended referent sets it apart from the other potential referents in either of these ways, then providing such proximity information is likely to be an efficient strategy for the speaker to use.

A spatially-based notion of proximity where this is used to refer to objects geographically close to the speaker and that is used to refer to objects geographically far from the speaker may seem intuitively attractive in these examples. However, it has been argued using evidence from psychology that this approach is over-simple and problematic. Kemmerer (1999) presents evidence that our perceptual assessments of proximity to and distance from ourselves do not fit well with the way that distal and proximal demonstratives are used crosslinguistically. Perceptually, a basic distinction is drawn between objects that are roughly within arm's length and those that are beyond arm's length. However, the use of proximal and distal demonstratives does not correspond to this distinction. Rather, according to Kemmerer, the spatial distinctions conveyed by the use of demonstratives, are much more abstract and relative.

Consider examples (29) and (30) (Kemmerer 1999:52, taken from Talmy, 1988): 
(29) This speck is smaller than that speck.

(30) This planet is smaller than that planet.

The specks referred to in (29) may be tiny, close together and within the speaker's reach, whilst the planets in (30) will be huge, far apart and remote from the speaker. In both cases, however, this and that may be used felicitously to refer to the individual specks and planets, respectively. Just as smaller is a relative notion dependent on the discourse context and the nature of the items it describes, so the proximity information conveyed by the demonstratives is also relative. According to Kemmerer, 'the proximal demonstrative this means simply "closer to the deictic center than that' and, conversely, the distal demonstrative that means simply "further from the deictic center than this"(1999:52). Thus a story begins to emerge where this and that are to be interpreted not only relative to a context and a deictic centre (e.g. a speaker), but also relative to one another. I follow Kemmerer's proposal and suggest that a consequence of this is that this and that are fundamentally contrastive in nature.

According to Wilson and Wharton, procedural meaning can be analysed in terms facilitating "the identification of the speaker's meaning by narrowing the search space for inferential comprehension, increasing the salience of some hypotheses and eliminating others" (2006:442). Elsewhere, Wilson describes the standard view of procedural expressions as being to "activate procedures whose main function is to help the hearer 
understand an utterance" (2011:12). In line with this, use of a demonstrative may be seen as adding an extra layer of activation to the hearer's representation of the intended referent by setting it in contrast with similar, but different, competing representations, thus guiding the hearer to the intended interpretation.

Kemmerer sums up by saying that demonstratives involve "semantic representations rather than concrete spatial representations; and the remarkable pragmatic flexibility of demonstratives is due to the fact that they are essentially deictic terms that cannot function apart from specific discourse contexts" (1999:56). This notion of relativity and the importance of the role played by the discourse context will be a central theme in my relevance-based account.

A further objection to analysing demonstratives in terms of purely spatial notions of proximity is that the contrasts they evoke are not restricted to the spatial domain. As Lakoff (1974) and Fillmore (1997) point out, an entity may be distinguishable by its relative proximity to the speaker in place, time, thought or discourse, and assessments based on these dimensions may not always coincide. For instance, a referent may be seen as proximal in discourse terms if it is the current focus of the exchange, although it may be distal in spatial terms. Take, for example, a case of so-called deferred reference, as 
discussed by Nunberg $(1995,2004)$. A customer hands a car key to a car park attendant and utters (31):

(31) This is parked out back.

Here, the speaker uses the demonstrated object (the key) as a proximal clue to the intended referent (the car), which itself is distal. The hearer's recognition of the speaker's intention to refer to the car (via the clue provided by the key) brings the mental representation of the intended referent into the current focus of the exchange. A representation of the intended referent (the car) is thus proximal in thought and discourse, although the object itself remains spatially distant.

Thus, assigning reference to a demonstrative expression requires identification of the deictic centre, on the one hand, and of the dimension in which a contrast is to be drawn, on the other. Identification will proceed, as always, via the relevance-theoretic comprehension procedure. A speaker aiming at optimal relevance should therefore construct any demonstrative expression so that the hearer reaches the intended interpretation by testing interpretative hypotheses in order of accessibility, and stopping when his expectations are satisfied. The deictic centre will typically be the present time, location or status/role of the speaker, as was the case in examples (27) and (28). However, it is important to 
acknowledge that, while common, this is not necessarily the case. For example, consider the exchange in (32):

(32) Dentist: Does this one hurt?

Patient: Yes, it's that one.

As Fillmore (1997:123) notes, the speaker may use a distal form for something relatively

close to her (her tooth) in order to present it from the hearer's perspective. As the tooth in question is in the patient's mouth, a speaker-based account of proximity relations would predict that the dentist should use the distal form and the patient the proximal form.

However, in this discourse context, it is the viewpoint of the dentist that is relevant, and so both interlocutors represent the situation from the dentist's point of view, and treat him as the deictic centre.

My argument so far might be summarized as follows. Demonstrative determiners encode procedural information. This procedural information relates to the proximity/distance of the intended referent $(M)$ to a deictic centre, as compared to competing instances of $N$ s. The effect should be to single out the intended referent and add an extra layer of activation to its representation so that it will be the most accessible one in the discourse context. Proximity and distance may be assessed on various dimensions, e.g. in spatial, temporal, emotional, thought or discourse terms. The hearer determines the deictic centre and the appropriate 
dimension of assessment in the same way as with other pragmatic processes: by following the path of least effort and stopping when the expectations of relevance raised by the utterance are satisfied.

So far in this section I have offered a procedural account of the contribution that demonstrative determiners make to what is explicitly communicated by an utterance.

However, while there are cases where the demonstratives clearly contribute to the explicitly communicated meaning, they do not necessarily always function in exactly the same way. Compare the examples in (21) and (22) with those in (23) and (24):

(21) I'll have a slice of this cake.

(22) l'll have a slice of that cake.

(23) We went for a lovely walk this afternoon.

(24) We went for a lovely walk that afternoon.

The use of this and that in (21) and (22) respectively is only appropriate when the intended referent is in the physical context, and the utterance is only likely to be felicitous if there is some other clue to the speaker's intention, such as a physical demonstration of where the speaker's attention is focused. Whilst such a demonstration may be as overt as a pointing gesture, it may also be a subtle cue such as eye gaze direction or directional nodding. In these cases something beyond the linguistically encoded meaning is required to convey the 
speaker's intention. As discussed above, drawing attention to the relative proximity of the intended referent by use of a demonstrative will only be relevant if doing so sets it apart from competing candidate referents. The speaker may add an extra layer of activation to the mental representation of the intended referent by contrasting it with relatively distal competitors. The contrast evoked by the use of a proximal/distal form as opposed to a definite description sets the intended referent apart from competing referents. Whilst the extra layer of activation is added to its representation as a result of the speaker's indication of where her attention is focused, use of a demonstrative form encourages the hearer to take this attention into consideration. As Neale suggests, using a demonstrative form to refer to an item $\varphi$ draws "attention to the fact that not any old $\varphi$ will do" (2007:103). By drawing attention to a particular entity in the physical environment, the speaker increases the accessibility of its representation, so that the hearer will test it first as a potential referent. The speaker's choice between this and that again comes down to the underlying procedures encoded by the terms, and the clues they give the hearer as to how inferential comprehension should proceed. Taking the speaker as the deictic centre, use of this, in this type of example, will encourage the hearer to expect a referent that is, in some salient way, relatively proximal to the speaker compared to another competing candidate referent. Accordingly, a hearer would be confused if the speaker were to utter (21) (I'll have a slice of 
this cake) whilst indicating a cake that was further away from her than some other salient cake. Thus, in these examples the proximity information encoded by the demonstrative determiner is a clue to where the speaker's attention is likely to be focused, and therefore what her referential intention is likely to be. Kaplan (1989) considered such cases to be 'true demonstratives', and he contrasted them with what he called 'pure indexicals'. Examples such as (23) and (24), or (33) and (34), are perfectly felicitous without any accompanying gesture, demonstration or further clue to the speaker's intention:

(33) In this section we will continue the argument.

(34) In that section we will continue the argument.

In examples of this type, there is invariably more than one potential referent, since neither afternoon nor section is uniquely denoting. However, in both cases involving the use of this, there is only one instance of each type that is likely to be considered proximal relative to the deictic centre of the speaker at the time of utterance. In both cases, too, the relevant type of proximity is likely to be temporal or discourse-related rather than spatial; this afternoon, will generally refer to the afternoon of the current day, and this section will generally refer to the 
section in which the current utterance occurs ${ }^{4}$. Utterances of this type can occur discourse initially, since there is no need for any further contextual information.

The situation is slightly different for indexical uses of the distal demonstrative that, as in (24) and (34). Whereas there is only one afternoon or one section which is likely to count as proximal, there will be more than one which could count as distal. That afternoon could refer to any afternoon on another day than the day of utterance, and that section could refer to any section apart from the current one. Following my relative, contrastive analysis of demonstratives, I predict that that will be used when the intended referent is further from the deictic centre than another candidate which could have been picked out by use of this, and is the most accessible non-proximal candidate. As we have seen, this picks out the current day or section, so that could be used to refer to any other day or section. However, interpretation proceeds in the usual way with the set of potential referents being narrowed to include only those which are relatively further away from the deictic centre than the current instance ${ }^{5}$. In effect, this rules out the afternoon of the present day, and the current section,

\footnotetext{
${ }^{4}$ There are corresponding true demonstrative readings available for these utterances. If, whilst poring over a holiday diary, a speaker points at a particular date and utters (23) the speaker's manifest intention to refer to the afternoon of the demonstrated day would override the indexical interpretation.

${ }^{5}$ Alternatively, we might view this as adding an extra layer of activation to the representations of the non-current instances. However, the result is the same and it is not clear how the two possibilities might be empirically distinguished.
} 
respectively. The hearer then follows the path of least effort, testing potential interpretations in order of accessibility. Thus, for an utterance of (24) (We went for a lovely walk that afternoon) to be felicitous, there should be one non-proximal afternoon whose representation is more accessible than those of the others ${ }^{6}$.

Consider the further examples in (35) and (36). Utterance (35) should be felicitous in any discourse context, and is acceptable in discourse initial position as a conversation starter. This is not the case with the distal alternative in (36):

(35) We are going on holiday this week.

(36) We are going on holiday that week.

The use of this constrains the set of potential referents to just those which are proximal to the deictic centre relative to competing candidate referents. Other things being equal, the only member of this set will be the week of the utterance. By contrast, (36) will only be felicitous when there is a particular non-proximal week whose representation is more accessible than those of any others. Use of the distal demonstrative in effect rules out the current week, but in doing so, it still leaves all other weeks as possible referents. For (36) to be felicitous, a representation of one of these candidate referents must be more accessible

\footnotetext{
${ }^{6}$ Or a highly accessible contextual assumption that combines with one potential referent more easily than the others to result in an interpretation that is relevant in the expected way.
} 
than those of the others. Utterance (36) might, for example, be appropriate if the speaker and hearer have been discussing when they might meet up next, and the hearer has suggested a particular date. In that case, a representation of the week which includes that date will be more accessible than those for other non-proximal weeks.

This pattern in the use of demonstratives has been acknowledged in various analyses of that, and strikingly similar conclusions have been drawn about when it may be used felicitously. According to Fillmore (1997:105), that is used when both interlocutors are aware of what is being talked about. For Ariel (1990:53) that requires identifiability by both speaker and addressee, and Gundel et al. (1993) capture a similar intuition by associating that $N$ with the cognitive status 'familiar'. Such generalizations fall out naturally from a relevance theory approach where interpretations are tested in order of accessibility. On such an approach, what makes the use of that felicitous in these discourse contexts is not the fact that both interlocutors necessarily know of what is being talked about. Rather, the felicitous use of that depends on one representation being more accessible to the hearer in the discourse context than its competitors. Discourse contexts of this type are highly likely to coincide with those where the intended referent fits the theory-specific definitions of 'familiar', 'identifiable' and so on. 
In sum, and having considered both 'true demonstrative' and 'pure indexical' uses of complex demonstratives, it seems that both categories may contribute to the explicit content of an utterance. The distinction boils down to a difference in the nature of the clues that the speaker provides to help the hearer retrieve the explicit content. In the pure indexical cases, the nature of the intended referent and the discourse context are such that the linguistically encoded meaning is enough. In the true demonstrative cases, however, the linguistic meaning is not sufficient, and further non-linguistic clues are needed. In a relevance-based account, however, these are just different means to the same end. The speaker intends the hearer to pick out a certain referent, and provides whatever linguistic or non-linguistic clues are necessary to achieve this aim.

\subsection{Beyond reference: Demonstratives and implicatures}

In the examples considered so far, the choice of determiner has affected the reference resolution process, which in turn has affected what is explicitly communicated by the utterance. However, there are other utterances where this does not seem to be the case. In such examples, substituting a complex demonstrative form for a definite description, or a proximal for a distal demonstrative, or vice versa, does not affect the way that reference is resolved. Consider examples (37)-(40):

(37) Section 3.2 focuses on what that procedural information might look like. 
(38) Section 3.2 focuses on what this procedural information might look like.

(39) Section 3.2 focuses on what the procedural information might look like.

(40) Section 3.2 focuses on what such procedural information might look like.

The use of that in (37) or this in (38), rather than the or even such, does not appear to affect the explicit content of the utterance. Both versions are not only also acceptable, but reference is resolved in the same way. This is in clear contrast to the examples in (21)-(22) above (I'll have a slice of this/that cake), where replacing the demonstrative with the in a multi-cake discourse context leads to infelicity. It seems, then, that replacing a demonstrative determiner with the definite article might provide a test for whether or not the demonstrative adds anything to the explicit content of an utterance. Consider utterance (41), taken from Powell (2010):

(41) That dog with three legs is called Lucky.

As Powell points out, the role played by the complex demonstrative that dog in (41) depends on the context in which is it uttered. If (41) is uttered whilst "standing in a room full of dogs, all but one of which have four legs" (Powell 2010:193), then the demonstrative determiner can be replaced by the definite article without affecting the felicity of the utterance, as in (42).

(42) The dog with three legs is called Lucky. 
However, if the speaker is standing in a room full of three-legged dogs, then the substitution leads to infelicity and probable reference failure. In the first discourse context, the conceptual information encoded by the nominal is sufficient to narrow the set of potential referents to a point where a representation of the intended referent (i.e. the dog with three legs) is the most accessible one, and so a definite description is sufficient. In the second discourse context, where there are several three-legged dogs, this is not the case, and further clues, in the form of information about relative proximity, probably combined with some type of non-linguistic demonstration, will be required. Whilst use of the definite article in (42) is only felicitous in the first discourse context, the complex demonstrative is acceptable in both, and does not affect how reference is resolved. As this is the case, it is necessary to consider what role the procedural information encoded by the demonstrative plays when it is not specifically required for derivation of the explicit content. To address this issue, we return to the relevance-theoretic notion that interpretation of an utterance involves three subtasks: identification of explicit content, identification of the intended contextual assumptions and identification of the intended contextual implications. So far, my account has focused on the first of these subtasks. However, in analysing interpretation of examples such as (37)-(40), we must consider the remaining two. These two tasks result in the derivation of implicatures, and therefore contribute to the implicit side of comprehension. 
The speaker may exploit procedural information to guide the hearer along the intended inferential path. If demonstratives encode procedural meaning, we would expect them to be used in this way to guide inferential processes contributing to both explicit content (i.e. reference resolution), and implicit content (i.e. implicatures). By applying relevance principles to the case of demonstratives, we can therefore incorporate into the analysis the role they may play in the inferential identification of implicatures. This is a role which has been largely overlooked in previous accounts.

Consider the examples in (43) and (44):

(43) Tartan was very popular in the 19th century. Prince Albert helped this trend by developing his own Balmoral tartan.

(44) Tartan was very popular in the 19th century. Prince Albert helped the trend by developing his own Balmoral tartan.

Although reference resolution is crucial to comprehension, a representation of the intended referent is already highly accessible in these cases, having been mentioned in the immediately preceding utterance. In both versions, the trend of wearing tartan is the most salient trend in the discourse context, and will therefore be tested first as a candidate referent by a hearer following the relevance-theoretic comprehension procedure. This will happen regardless of whether or not encoded information about (discourse) proximity is 
provided. Since the identity of the intended referent is already taken care of, the speaker has available the option of using information about proximity encoded in the demonstrative determiner to create extra or different effects (so long as this does not interfere with correct assignment of reference). In cases of this type, the extra effort required to process the procedural information provided by the speaker is justified only if it yields an adequate range of additional inferential effects.

We then need to consider what form these additional effects might take. To avoid any suggestion that this and that are ambiguous, we want the procedural information encoded by each demonstrative to remain constant in all cases. Applying my earlier analysis, then, utterance (43) (this trend) indicates that the trend of wearing tartan is closer to the deictic centre (in spatial, temporal or discourse terms) than some other competing trend. Although there is no competing trend in the discourse context, the hearer still presumes that the speaker is aiming at optimal relevance, and will therefore infer the existence of a potential competitor or competitors from the use of the demonstrative form. Thus, while the nominal part of the referring expression is uniquely denoting in the discourse context, and so use of a definite description would be felicitous, use of the demonstrative encourages the hearer to treat the intended referent as non-unique. This in turn evokes an implicit contrast effect which yields a wide range of weak implicatures. Such tacitly contrastive uses of 
demonstratives might be analysed along similar lines to the stylistic effects resulting from repetition of words or phrases. Sperber and Wilson suggest that in example (45) the repetition is justified, not by some "strong and predictable contextual implication", but by "a more diversified expansion of the context and by a wider array of weaker implicatures" (1986/95:221):

(45) My childhood days are gone, gone.

Blakemore $(1992,2008)$ discusses further examples. According to Sperber and Wilson, "poetic effects create common impressions rather than common knowledge" (1986/95:224), and I suggest that demonstratives can also contribute to the overall relevance of an utterance in this way. In (43) the contrast implicit in the use of a demonstrative stylistically highlights the wearing of tartan as one particular trend amongst many. This may then lead to a range of further effects depending on the interaction between this implied contrast and the wider discourse context. For example, the speaker may be implicating that the fondness for tartan was just one of many trends (as opposed to serious preoccupations).

Alternatively, it may just be a means of conveying a sense of continuity, indicating to the hearer that the subject matter has not changed and the focus remains on the same topic. The nature of the weak implicatures that will be derived may also be influenced by other factors such as intonation and tone of voice. Similar weak inferential effects are conveyed 
by examples (37)-(40). Here, both this and that are acceptable, because it is not the relative proximity of the referent itself that is relevant, but the implicit contrast with alternative possible referents. The choice of a demonstrative form over the definite article perhaps carries a tacit acknowledgement that the discussion which forms the object of the sentence is focused on one particular type of procedural information, where other types may be possible. Again, an element of contrast is introduced. The choice between this and that in such cases is likely to be driven by a variety of such subtle and interacting factors.

These subtle differences and apparent borderline cases support the hypothesis that the information about proximity encoded by the determiner can vary along several dimensions. They also reinforce the claim that proximity should not be characterised as an inherent property of an entity itself. Rather, it should be viewed as something that is computed from moment to moment, assigned to the referent online and subject to change as the discourse and discourse context develop.

\subsection{Revisiting demonstrative functions}

Recall that descriptive, taxonomic approaches to demonstratives have sought to divide their use and functions into board categories: gestural/spatio-temporal, anaphoric/discourse, symbolic/emotional, etc. I have suggested that these categories are both blurred at the edges and theoretically uninteresting, and argued that demonstratives should be analysed 
instead as encoding procedural information about relative proximity, broadly construed. I have tried to show how this procedural meaning may guide the hearer in resolving reference, and so contribute to the explicit content of an utterance, or it may contribute to the derivation of implicatures and other inferential effects. In this section, I revisit the range of uses identified in section 2.1, and show how they might fit into this procedural, relevance-driven approach.

First, the examples classified by Fillmore and Lakoff as spatial / gestural involve use of the encoded procedural information to guide the hearer during reference resolution, and hence in the derivation of explicit content. The speaker indicates to the hearer that she expects him to pick out a certain referent from among two or more competitors, using the demonstrative form, perhaps accompanied by a physical demonstration, as a clue to her intended meaning. In these cases, the procedural information encoded by the determiner is crucial for reference resolution purposes, and substitution of a definite determiner for the demonstrative will be infelicitous.

Next there are cases where the demonstratives serve an anaphoric function within the discourse, such as in (13) and (14), repeated here:

(13) John was late, and that made Mary angry.

(14) This is the plan: tell nobody. 
Application of the substitution test might seem to indicate that these function in a similar way.

As with the gestural cases, substitution of the definite determiner for a demonstrative is unacceptable, as in (46):

(46) *John was late, and the made Mary angry

However, the cases are not really parallel, since (46) is not merely infelicitous but ungrammatical. As has often been noted, the definite determiner differs from the demonstrative determiners in its inability to stand alone. Whilst this and that can function as either complex or bare demonstratives, the must be accompanied by conceptual information or replaced by it, as in (47):

(47) John was late, and it made Mary angry

Since in these cases, unlike the spatial / gestural ones, this substitution does not affect reference resolution, we can conclude that here the procedural information encoded by the demonstrative does not contribute to explicit content. Rather, use of the demonstrative in (13) introduces a contrast effect, and underlines the fact that it was John's lateness (and not anything else) that made Mary angry. Whilst the explicitly communicated meaning is the same in (47), the absence of a demonstrative leads to a loss of this extra, contrastive effect. This contrastive analysis is supported by the fact that that in (13) can carry contrastive 
stress, while it in (47) cannot ${ }^{7}$. In many cases, it is the contrast effect itself that is relevant, and the choice between the demonstratives is marginal. In examples (37) and (38), for instance, (Section 3.2 focuses on what that/this procedural information might look like) both demonstratives are equally acceptable, and the choice between them might come down to subtle stylistic factors (e.g. the desire to avoid a repetition of this). The speaker must choose one or other demonstrative determiner, but the choice itself may not be significant.

A final challenge for any account of demonstratives is to shed some light on the wide range of disparate examples identified in section 2.1 and variously described as metaphorical, emotional, empathetic, recognitional, affective or symbolic. Recall that these uses were claimed to create effects described variously as camaraderie, closeness, vividness, solidarity and sympathy.

One advantage of a relevance theory approach is that it makes it possible to provide a unified account, since a wide range of different effects can arise from interaction between encoded meaning and discourse context, guided by the hearer's presumption of optimal relevance.

I have argued that the relative nature of the encoded information about proximity can result in a contrast effect. I will now consider how this effect can be worked out in different

\footnotetext{
${ }^{7}$ See Scott (2011) for further discussion of contrastive stress and procedural meaning.
} 
ways in different contexts, to yield different types of weak implicatures, stylistic or poetic

effects and attitudinal information. As Neale comments, "uses of demonstratives upon which they are no more than stylistic variants of definite descriptions are legion" (2007:105).

Consider examples (16) and (17), repeated here for convenience:

(16) There was this travelling salesman, and he...

(17) How's that throat?

In both cases, the use of a demonstrative form is claimed to create a sense of camaraderie, intimacy or vividness. I want to suggest that this effect results from communication of the speaker's attitude to the referent, a possibility that has been overlooked in previous accounts. In examples such as (16) the proximal demonstrative is used in place of the indefinite article ${ }^{8}$. According to Lakoff, this use "gives greater vividness to the narrative" and "involve[s] the addressee in it more fully" (1974:347). If the speaker had merely wanted to identify the intended referent, the most straightforward way would have been to use the indefinite article, as in (48):

(48) There was a travelling salesman, and he...

${ }^{8}$ Cross-linguistic evidence from lonin (2006) suggests that indefinite this does not necessarily belong in a unified account with definite demonstratives. However, my procedural approach does seem to have something to say in such cases. 
The hearer is therefore entitled to expect more or different effects from the use of the proximal demonstrative. On my account, the effects identified by Lakoff can be explained in the following way. Use of the demonstrative presents the intended referent as close to the deictic centre. As a result, despite the fact that the travelling salesman is being introduced into the discourse for the first time, the hearer is encouraged to see him as emotionally closer or more special to the speaker than other potential referents. What creates the sense of intimacy between speaker and hearer is the fact that he is expected, without any further help from the speaker, not only to realise that she has a certain range of competitors in mind, but to recognise which of them she is talking about. It is notable that there is no comparable use of that, and indefinite this is mainly restricted to casual or informal registers where implied intimacy between speaker and hearer would not be inappropriate.

Use of the distal demonstrative in examples such as (17) has similarly been claimed to create a 'sense of intimacy' between the doctor and her patient. This could be viewed as surprising on a simple metaphorical analysis of this category of uses. We might expect to find the proximal demonstrative used to signal emotional intimacy, and the distal form used to signal emotional distance. However, this is not the case, and my procedural analysis of demonstratives again links the effect to some tacit contrast that is evoked by use of the demonstrative. 
As in the previous cases, a representation of the intended referent is highly accessible to the hearer, and information about the proximity of the referent to the speaker is not required for reference resolution. The hearer will therefore look for extra or different effects to offset the effort of processing this otherwise superfluous linguistic material.

Use of a demonstrative form sets the throat in question apart as of special interest to the doctor (by setting it in contrast with other throats), and indicates that both doctor and patient have discussed it before. In Cornish's terms, "that functions interactively to create a sort of solidarity between discourse participants, establishing common ground" (2001:305). As discussed in section 3.2, felicitous uses of that in cases without a demonstration of some kind rely on one particular instance of the nominal (in this case throat) being more activated and hence more accessible than any others. By referring to the patient's throat in this way, the speaker communicates that she considers it the most activated, accessible, perhaps important throat in the discourse context. Again we return to Neale's observation that use of that $\varphi$ "draws attention to the fact that not any old $\varphi$ will do" (2007:103).

\section{Conclusion}

In this paper, I have tried to show how the various uses of demonstrative forms can be analysed using the relevance theory notion of procedural meaning. Interpretation of utterances containing these items is guided by the relevance-theoretic comprehension 
procedure: the hearer follows a path of least effort in looking for implications, and stops when his expectations of relevance are satisfied. The procedural information encoded by the determiners narrows the search space and encourages him to look for inferences in certain directions. In some cases these inferences will contribute to reference resolution, and hence to explicit content, and in others to the derivation of implicatures.

The demonstratives encode a procedure, and as interpretation proceeds, that procedure interacts with the discourse context to affect not just the reference resolution process, but the overall interpretation. According to relevance theory, the sub-processes involved in interpretation take place in parallel, as the hearer follows the path of least effort in looking for enough implications (or other cognitive effects) to satisfy his expectation of relevance. On this account, then, the question of which function of demonstratives (spatial-temporal, discourse, metaphorical, emotional, etc.) is basic and which is derived does not arise. The underlying, conventional meaning encoded by the demonstratives is procedural, and all functions are derived by interaction between this procedural meaning and the discourse context, guided by the search for optimal relevance.

A further advantage of approaching the data using the relevance-theoretic notion of procedural meaning is that it becomes possible to provide a unified account of both bare demonstratives and complex demonstratives. The procedure remains the same in both 
cases, and the demonstrative contributes to explicit meaning in some cases, and to implicit meaning in others.

Finally, my focus in this paper has been on the English demonstrative system. Various other languages, including Greek, Japanese and Spanish, employ a three-way system which distinguishes proximal, distal and medial referents, while other systems may make still further distinctions (Diessel, 1999; Levinson, 2004). By treating proximity as a relation that is computed online as the discourse progresses, it should be possible to incorporate these further distinctions into a procedural approach.

In sum, demonstrative determiners are a means by which the speaker may make her utterance optimally relevant. They may narrow the set of potential referents to a point where a representation of the intended referent is the most accessible one for the hearer, or they may be highlighting devices used to increase the accessibility of the intended referent for the same purpose. When a representation of the referent is already highly accessible to the hearer, the speaker may use a demonstrative form to achieve extra or different inferential effects. This may simply involve highlighting a perceived contrast which gives access to a range of implications or implicatures, or it may encourage the derivation of weak attitudinal implicatures. As I have tried to show, these effects are varied and wide-ranging. However, 
they can all be traced back to the encoded proximity information, its interaction with the

context, and the speaker's goal of achieving optimal relevance.

\section{Acknowledgements}

Many thanks to Deirdre Wilson for the discussions, suggestions and, most of all, inspiration

behind this paper. I am also very grateful to three anonymous referees for their comments

on earlier drafts.

\section{References}

Amfo, N., 2007. Akan Demonstratives. In: Payne, D. L., Peña, J. (Eds), Selected Proceeding of the $37^{\text {th }}$ Annual Conference on African Linguistics. Somerville MA, Cascadilla, pp. 134148.

Anderson, S. R., Keenan, E. L., 1985. Deixis. In: Shopen, T. (Ed), Language Typology and Syntactic Description. Cambridge: Cambridge University Press, pp. 259-308.

Ariel, M., 1990. Accessing Noun Phrase Antecedents. London: Routledge.

Ariel, M., 2001. Accessibility theory: an overview. In: Sanders, T., Schliperoord, J., Spooren, W. (Eds), Text representation: linguistic and psycholinguistic aspects. Amsterdam: John Benjamins, pp. 29-87.

Blakemore, D., 1987. Semantic Constraints on Relevance. Oxford: Blackwell.

Blakemore, D., 1992. Understanding Utterances. Oxford: Blackwell.

Blakemore, D., 2000. Indicators and procedures: nevertheless and but. Journal of Linguistics 36, 463-486.

Blakemore, D., 2002. Relevance and Linguistic Meaning: the Semantics and Pragmatics of Discourse Markers. Cambridge: Cambridge University Press.

Blakemore, D., 2007. Constraints, concepts and procedural encoding. In: Burton-Roberts, N. (Ed), Pragmatics. Basingstoke: Palgrave MacMillan, pp. 45-66.

Blakemore, D., 2011. On the descriptive ineffability of expressive meaning. Journal of Pragmatics 43 (14), 3537-3550.

Carston, R., 2002. Thoughts and Utterances : The Pragmatics of Explicit Communication. Oxford: Blackwell. 
Carston, R., 2004. Relevance theory and the saying/ implicating distinction. In: Horn, L., Ward, G. (Eds.,) Handbook of Pragmatics. Oxford: Blackwell.

Chen, R., 1990. English demonstratives: a case of semantic expansion. Language Sciences 12(2-3), 139-153.

Cheshire, J., 1996. That jacksprat: an international perspective on English that. Journal of Pragmatics 25, 369-93.

Cornish, F., 2001. "Modal" that as determiner and pronoun: the primacy of the cognitiveinteractive dimension. English Language and Linguistics 5(2), 297-315.

Diessel, H., 1999. Demonstratives: Form, Function and Grammaticalization. Amsterdam: John Benjamins.

Fillmore, C. J., 1997. Lectures on Deixis. Stanford, CA.: CSLI Publications.

Fodor, J., 1983. The Modularity of Mind. Cambridge, Mass: MIT Press.

Glover, K. D., 2000. Proximal and distal deixis in negotiation talk. Journal of Pragmatics 32 (7), 915-926.

Gundel, J. K., 2010. Reference and Accessibility from a Givenness Hierarchy Perspective. International Review of Pragmatics 2(2),148-168.

Gundel, J. K., Hedberg, N., Zacharski, R., 1993. Cognitive status and the form of referring expressions in discourse. Language 69(2), 274-307.

Gundel, J. K., Mulkern, A. E., 1998. Quantity implicatures in reference understanding. Pragmatics and Cognition, 6(1/2), 21-45.

Hall, A., 2007. Do discourse markers encode concepts or procedures? Lingua 111(1), 149174.

Halliday, M. A., 1985. An Introduction to Functional Grammar. London: Edward Arnold Ltd. Hedley, P., 2007. Anaphora, Relevance and the Conceptual/Procedural Distinction. Magdalen College, Oxford.

Huddleston, R., Pullum, G. K., 2002. The Cambridge Grammar of the English Language. Cambridge: Cambridge University Press.

Ionin, T., 2006. This is definitely specific: specificity and definiteness in article systems. Natural Language Semantics 14(2),175-234.

Iten, C., 2005. Linguistic Meaning, Truth Conditions and Relevance: the case of concessives. Basingstoke: Palgrave MacMillan.

Janssen, T. J., 1995. Deixis from a cognitive point of view. In: Contini-Morava, E., Goldberg, B. S. (Eds), Meaning as Explanation: Advances in Linguistic Sign Theory. Berlin and New York: Mouton de Gruyter, pp. 245-270.

Kaplan, D., 1989. Themes from Kaplan. Oxford: Oxford University Press.

Kemmerer, D., 1999. "Near" and "far" in language and perception. Cognition 73(1),35-63. 
Klinge, A., 2006. The unitary procedural semantics of the, this and that. Acta Linguistica Hafniensia: International Journal of Linguistics 38(1), 54-77.

Kruisinga, E., 1925-32. A Handbook of Present Day English. 4th ed. Utrecht: Kemink. Lakoff, R., 1974. Remarks on This and That. Chicago, University of Chicago.

Leonetti, M., 2000. The asymmetries between the definite article and demonstratives: A procedural account. Budapest.

Levinson, S. C., 1983. Pragmatics. Cambridge: Cambridge University Press.

Levinson, S. C., 2004. Deixis. In: Horn, L. R., Ward, G (Eds.), The Handbook of Pragmatics. Oxford: Blackwell, pp. 97-121.

Lyons, J., 1977. Semantics. Cambridge: Cambidge University Press.

Maes, A., 1996. Nominal Anaphors, Markedness, and the Coherence of Discourse. Leuven: Peeters.

Neale, S., 2007. Heavy Hands, Magic, and Scene-Reading Traps. European Journal of Analytic Philosophy 3(2), 77-132.

Nunberg, G., 1979. The non-uniqueness of semantic solutions: Polysemy. Linguistics and Philosophy 3, 143-184.

Nunberg, G., 1995. Transfers of meaning. Journal of Semantics12, 109-132.

Nunberg, G., 2004. The pragmatics of deferred interpretation. In: Horn, L. R., Ward, G (Eds.), The Handbook of Pragmatics. Oxford: Blackwell, pp. 344-364.

Powell, G., 1998. The deferred interpretation of indexicals and proper names. UCL Working Papers in Linguistics 10, 1-32.

Powell, G., 2010. Language, Thought and Reference. Hampshire: Palgrave MacMillan.

Quirk, R., Greenbaum, S., Leech, G., Svartvik, J., 1985. A Comprehensive Grammar of the English Language. New York: Longman.

Reboul, A., 1998. A relevance theoretic approach to reference. In: Acts of the Relevance Theory Workshop. Luton, University of Luton, pp. 45-50.

Reboul, A., 1999. Reference, agreement, evolving reference and the theory of mental representations. In: Coene, M. (Ed), Traiani Augusti vestigia pressa sequamur :studia 1 lingvistica in honorem L. Tasmowki,. Padova: Unipress, pp. 601-616.

Riddle, E. M., 2010. Vantage Theory and the use of English demonstrative determiners with proper nouns. Language Sciences 32, 225-240.

Scott, K., 2011. Beyond Reference: Concepts, Procedures and Referring Expressions. In: Escandell-Vidal,V., Leonetti, M., Ahern, A. (Eds), Procedural Meaning: Problems and Perspectives. Bingley: Emerald, pp. 183-203. 
Sperber, D., 2005. Modularity and relevance: How can a massively modular mind be flexible and context-sensitive?. In: Carruthers, P., Laurence, S., Stich, S. (Eds), The Innate Mind: Structure and Content. Oxford: Oxford University Press, pp. 53-68.

Sperber, D., Wilson, D., 1986/95. Relevance: Communciation and Cognition. Second edition (with postface) Oxford: Blackwell.

Sperber, D., Wilson, D., 2002. Pragmatics, modularity and mind-reading. Mind and Language 17(1), 3-23.

Strauss, S., 1993. Why this and that are not complete without it. Proceedings of the $29^{\text {th }}$ Regional Meeting of the Chicago Linguistic Society: i: The Main Session. Chicago Linguistic Society, pp. 403-417.

Strauss, S., 2002. This, That and It in Spoken American English: a demonstrative system of gradient focus. Language Sciences, 24(2), 131-152.

Talmy, L., 1988. The relation of grammar to cognition. In: Rudska-Ostyn, B. (Ed), Topics in Cognitive Linguistics. Amsterdam: John Benjamins, pp. 165-206.

Wharton, T., 2003. Interjections, language and the 'showing-saying' continuum. Pragmatics and Cognition 11, 39-91.

Wharton, T., 2009. Pragmatics and Non-Verbal Communication. Cambridge: Cambridge University Press.

Wilson, D., 2011. The conceptual-procedural distinction: past, present and future. In: Escandell-Vidal,V., Leonetti, M., Ahern, A. (Eds), Procedural Meaning: Problems and Perspectives. Bingley: Emerald, pp. 3-31.

Wilson, D., Sperber, D., 1993. Linguistic form and relevance. Lingua 90, 1-25.

Wilson, D., Sperber, D., 2004. Relevance theory. In: Horn, L. R., Ward, G (Eds.), The Handbook of Pragmatics. Oxford: Blackwell, pp. 607-632.

Wilson, D., Sperber, D., 2012. Meaning and Relevance. Cambridge: Cambridge University Press.

Wilson, D., Wharton, T., 2006. Relevance and Prosody. Journal of Pragmatics 38 (10), 1559-1579. 